\title{
The influence of plant species richness on stress recovery of humans
}

\author{
Petra Lindemann-Matthies ${ }^{1,2}$ and Diethart Matthies $^{3}$ \\ ${ }^{1}$ Institute of Biology, Karlsruhe University of Education, Karlsruhe, Germany \\ ${ }^{2}$ Institute of Evolutionary Biology and Environmental Sciences, University of Zurich, Zurich, Switzerland \\ ${ }^{3}$ Department of Ecology, University of Marburg, Marburg, Germany \\ Correspondence: Petra Lindemann-Matthies (petra.lindemann-matthies@ph-karlsruhe.de)
}

Received: 10 March 2018 - Revised: 5 August 2018 - Accepted: 9 August 2018 - Published: 29 August 2018

\begin{abstract}
Natural sceneries or single plants may have positive influences on human health. Here we show that plant species richness can positively influence recovery from stress. Meadow-like arrays of different species richness $(1,16,32,64$ species) were presented to visitors $(n=171)$ of a popular park in Zurich, Switzerland (one array per participant). Participants' systolic blood pressure was measured twice: directly after they had been stressed and once again after a $2 \mathrm{~min}$ post-stress relaxation period during which they looked at one of either the meadow-like arrangements of plants in pots or at bare ground, shielded on three sides by a tent-like structure. The decrease in blood pressure was larger when respondents could view an arrangement of plants instead of ground without vegetation. Relaxation was strongest at intermediate species richness (32 species). Age, gender, and a person's attachment to nature did not influence relaxation. Our results indicate that species-rich vegetation may contribute to recovery from stress which should be considered in landscape management and planning.
\end{abstract}

\section{Introduction}

Biodiversity represents the foundation of ecosystems that, through the services they provide, affect human well-being, with health as one of its main components (MEA, 2005). According to the World Health Organization (WHO, 2018), "health is a state of complete physical, mental and social well-being and not merely the absence of disease or infirmity". However, little is known about how biodiversity, and species richness in particular, contribute to human health (Dallimer et al., 2012; Fuller et al., 2007; Southon et al., 2018). In a novel approach, we used manipulative experiments and a design analogous to that of diversity-ecosystem function experiments (e.g. Hector et al., 1999) to investigate whether plant species richness, as one component of biodiversity, influences the stress recovery of humans. Stress recovery was calculated as the difference between peak systolic blood pressure after stress and the level recorded at the end of a post-stress resting period.

While influences of plant diversity on human health have hardly been investigated, influences of plants as such or, more generally, natural sceneries, are rather well studied.
Natural views compared with views that lack natural elements have been found to elicit positive feelings and to foster restoration from anxiety or stress and even recovery from surgery (e.g. Hartig et al., 2003; Ulrich, 1984; Ulrich et al., 1991). Stress reduction theory (SRT) posits a healing power of nature that lies in an unconscious, autonomic response to natural elements that can occur without recognition and most noticeably in individuals who have been stressed before the experience (Bratman et al., 2012; Ulrich, 1993). An evolutionary perspective predicts that because humans evolved over a long period of time in natural environments, people are to some extent physiologically and perhaps psychologically adapted to natural, as opposed to urban, physical settings (Kellert, 1993). Particular qualities of a scene such as moderate depth and complexity, the presence of a focal point, gross structural qualities, and natural contents such as vegetation and water can evoke positive emotions, sustain nonvigilant attention, restrict negative thoughts, and so aid a return of autonomic arousal to more moderate levels (Hartig et al., 2003; Kaplan and Kaplan, 1989; Kaplan et al., 1998). 
In a frequently cited study by Ulrich (1984), patients after a cholecystectomy recovered faster from surgery and had less postoperative complications when their hospital windows were looking out on a natural scene instead of facing a brick building wall. In a comparable study, the presence of indoor plants also shortened postoperative recovery periods (Park and Mattson, 2009). Patients assigned to rooms with plants or flowers had shorter hospitalizations, fewer intakes of analgesics, lower ratings of pain, anxiety, and fatigue, and more positive feelings and higher satisfaction about their rooms when compared with patients of a control group (identical rooms, no plants at all). Moreover, patients exposed to indoor plants reported lower levels of experienced stress compared to control conditions (Beukeboom et al., 2012; Dijkstra et al., 2008). Similarly, classroom views to green landscapes significantly increased the recovery of high-school students from stressful experiences and caused better performance on tests of attention than views to a built space (Li and Sullivan, 2016). Likewise, stressed respondents recovered much faster (decline in blood pressure) when they were sitting in a room with a tree view instead of a viewless room (Hartig et al., 2003).

Several studies have investigated the influence of indoor plants on emotions and stress recovery. Office workers had more positive emotions in the presence of plants (Ikei et al., 2014; Larsen et al., 1998) and were calmer and less anxious when indoor plants were present or when their office windows were facing natural sceneries instead of artefactdominated ones (Bringslimark et al., 2007; Chang and Chen, 2005). Sick leave, but also punishment records due to misbehaviour, were also reduced among high-school students after plants had been placed in their classroom (Han, 2009). The presence of plants can also lead to faster reaction times and better performance in association tasks and cognitive tests (e.g. Han, 2009; Lohr et al., 1996; Shibata and Suzuki, 2002). A recent study investigated the restorative impacts of green walls with living plants in primary schools in the Netherlands (van den Berg et al., 2017). Children in classrooms in which a green wall was placed, compared to children in control groups, evaluated their classrooms more positively and also scored better on a test for selective attention.

In a large Danish survey, associations between health and distance from one's private home to the nearest green space were found (Stigsdotter et al., 2010). Study participants living more than $1 \mathrm{~km}$ away from a green space had higher odds of experiencing stress than those living less than $300 \mathrm{~m}$ away. Moreover, the more often respondents visited green spaces, the less they experienced stress (see also Maas et al., 2006). However, little research has been carried out on the effects of the quality of green space, e.g. the contribution of structural diversity, evenness, species richness, or the presence of certain plant and animal species, on human health.

Recent studies indicate that psychological benefits of green space increase with levels of species richness (Dallimer et al., 2012; Fuller et al., 2007). In these studies, partici- pants had to state in situ their opinion on different statements, measuring likelihood of recovery from mental fatigue and opportunity for reflection, as well as emotional attachment to and personal identity gained from the green space. Wellbeing was positively related to perceived species richness of birds, butterflies, and plants (Dallimer et al., 2012). However, when actual species richness was tested, well-being declined with greater plant diversity, and there was no pattern with butterfly species richness. The authors concluded that there may be other aspects of biodiversity, such as the role of charismatic species, which may influence well-being more strongly (Dallimer et al., 2012). In diversity manipulation experiments, the presence of certain plant species indeed explained some of the variation in aesthetic appreciation of the grassland communities that could not be explained by their species richness (Lindemann-Matthies et al., 2010a). The presence of certain herbs with brightly coloured flowers like Papaver rhoeas increased the appreciation of communities, whereas the presence of grasses like Lolium perenne decreased it. However, in the analyses, species richness always explained more of the overall variation than species identity.

To investigate whether plant species richness influences stress recovery of humans, we presented meadow-like arrays of different species richness and species composition to visitors of a popular park close to the University of Zurich Irchel Campus. The location was chosen because a nearby common garden provided water, space, and shelter for the plants during our study period. We measured stress recovery and also recorded participants' self-estimated degree of attachment to nature, as well as gender and age, as these variables have been found to be influential on stress recovery (e.g. Cervinka et al., 2012; Stigsdotter et al., 2010) and visual responses to green space (e.g. Lindemann-Matthies and Bose, 2007). Based on the literature, we made the following predictions.

P1. Stress recovery, measured as the difference between systolic blood pressure directly before and after the post-stress relaxation time, will be larger when respondents can view a meadow-like array of plants rather than ground without vegetation, as natural elements have a larger stress-reducing effect than artificial objects (Beukeboom et al., 2012; Chang and Chen, 2005; Lohr et al., 1996).

P2. With increasing plant species richness, relaxation will increase, but at the highest levels may decrease again (Lindemann-Matthies et al., 2010a; Shanahan et al., 2015).

P3. Apart from species richness, the proportion of herbs present will explain some of the variation in stress relaxation. Studies indicate that herbs are visually preferred over grasses (Lindemann-Matthies and Bose, 2007; Lindemann-Matthies et al., 2010b). 
Table 1. Description of the 10 different meadow-like arrays and the bare ground treatment.

\begin{tabular}{lrlr}
\hline $\begin{array}{l}\text { Treatment } \\
\text { no. }\end{array}$ & $\begin{array}{r}\text { Number of } \\
\text { species }\end{array}$ & $\begin{array}{r}\text { Species } \\
\text { combination }\end{array}$ & $\begin{array}{r}\text { Proportion } \\
\text { of herbs }(\%)\end{array}$ \\
\hline 1 & 1 & Papaver rhoeas monoculture & 100.0 \\
2 & 1 & Centaurea cyanus monoculture & 100.0 \\
3 & 1 & Briza media monoculture & 0.0 \\
4 & 1 & Lolium perenne monoculture & 0.0 \\
5 & 16 & 1 herb and 15 grasses & 6.3 \\
6 & 16 & 8 herbs and 8 grasses & 50.0 \\
7 & 32 & 20 herbs and 12 grasses & 62.5 \\
8 & 32 & 23 herbs and 9 grasses & 71.9 \\
9 & 64 & 47 herbs and 17 grasses & 73.4 \\
10 & 64 & 49 herbs and 15 grasses & 76.6 \\
11 & 0 & Sandy path without vegetation & - \\
\hline
\end{tabular}

P4. Socio-demographic variables such as age and gender, but also a person's attachment to nature, might influence blood pressure and perception of meadow-like arrays, and thus influence stress recovery (Cervinka et al., 2012; Clark et al., 2014; Collins and O'Callaghan, 2008; Rappe et al., 2006; Shibata and Suzuki, 2004).

\section{Materials and methods}

\subsection{Study design and data collection}

To test our predictions, we cultivated more than 700 plants belonging to 71 grassland species ( 55 herbs, 16 grasses) individually in square pots $(9 \mathrm{~cm} \times 9 \mathrm{~cm})$ in a greenhouse. Plants differed in their flower colour, height, and form of leaves. Plants were arranged in meadow-like arrays of different plant species richness $(1,16,32$, and 64 species) and presented to the public. Levels of species richness were chosen to represent a wide range in the number of species. Each array consisted of $64(8 \times 8)$ pots. The pots were arranged at random in a wooden box $(70 \mathrm{~cm} \times 70 \mathrm{~cm} \times 10 \mathrm{~cm})$ that gave the impression of a meadow. Within an array the number of individuals of each species was similar and the spatial distribution of the species was random. To differentiate between the effects of species richness and species composition (e.g. proportion of herbs to grasses), two different arrangements of plants for the diversity levels 16,32 , and 64 were always made (as shown in Table 1).

For the monoculture arrays, plant species were chosen that had influenced perceived attractiveness in previous experiments (Lindemann-Matthies et al., 2010a) and that also differed in flower colour and functional group. Poppy ( $\mathrm{Pa}$ paver rhoeas) and cornflower (Centaurea cyanus) were chosen as representatives for species with a positive influence, and perennial rye grass (Lolium perenne) was chosen as a species with a presumably negative influence. In both herb monocultures, all plants were flowering. To have an additional grass species, quaking grass (Briza media) was included, which, in the previous experiments, had a neutral ef- fect on perceived attractiveness (Lindemann-Matthies et al., 2010a). In the other diversity levels (16, 32, and 64 species), the four species that were presented as monocultures were also partly included. Species included in these arrays were selected to represent various mixtures of grasses and flowering forbs. Species in the arrays were arranged at random.

In summer 2010, data were collected on warm and sunny afternoons, always at the same place, a crossing of two paths in a public park in Zürich-Irchel, Switzerland. Before the start of experiments, background noises were observed on several days. Occasional background noise was mainly produced by airplanes and park visitors, including dogs, but was rather infrequent and thus not considered a disturbance to the experiment. Otherwise, birds were always singing and a stream was flowing by, resulting in an unobtrusive, normal soundscape for a park.

On each day of the study, one individual meadow-like array was placed on the path, always in the same spot, and covered on four sides by a tent-like structure. A chair was put in front of the tent, facing it. Park visitors (all adults) were approached and asked to participate in the experiment. They were informed that they would participate in a study on the effects of plants on human health and anonymity was assured to them. Overall, $80 \%$ of all persons addressed participated ( $n=171$; between 10 and 24 persons on each day of study).

Participants were asked to sit on the chair, facing the tent. They were then stressed with a colour-word test (Stroop test) widely used in clinical practice and investigation (e.g. Tulen et al., 1989). In this test, the names of different colours (e.g. yellow, blue, red, or green) are printed in colour ink on paper. However, the written colour names differ from the colour ink they are printed in (e.g. the word "yellow" can be printed in red). Test persons have to name, as fast as possible, not the written words, but the ink colour the words are written in (or vice versa). To boost stress, we promised participants a reward (chocolate) if they could complete the test in less than 2 min. Directly after the test, systolic and diastolic blood pressure were measured with a wrist monitor (OMRON R6 wrist blood pressure monitor, Omron Healthcare Europe, B.V., Hoofddorp, the Netherlands) that has been used in clinical studies (e.g. Stanković and Nikolić, 2016). The front cover of the tent was then opened. Respondents were asked to look at the meadow-like array or, on one day of the study, just the ground of the sandy path. After 2 min their blood pressure was measured again.

To test for the influence of socio-demographic variables and a person's affinity to green space, participants were finally asked about their age, gender, and self-estimated degree of attachment to nature (indicated on a $10 \mathrm{~cm}$ scale, anchored at the ends with "very low" and "very high"). Moreover, they were asked about their impressions during the experiment. To thank them for their participation, participants received some sweets and a package of wild flower seeds. Directly afterwards the front part of the tent was closed again and, after some minutes, the next person approached. The time 
lag should ensure that participants had not already seen the meadow-like array when the tent was open. The experiment was pilot-tested on half a day with 10 visitors to the park and showed that the method was suitable to investigate people's responses to plant species richness. It took about $20 \mathrm{~min}$ to accomplish all tasks (addressing a visitor, carrying out the experiment, answering questions, and making notes on comments).

\subsection{Study participants and data analysis}

Study participants, 107 women and 64 men, were between 18 and 87 years old (mean age $=46$ years). They regarded themselves as rather attached to nature (mean score of $8.4 \pm 0.12$ on the $10 \mathrm{~cm}$ scale). Stress recovery was measured as the difference between systolic blood pressure directly before and after the post-stress relaxation period. Diastolic and systolic blood pressure measurements were correlated (stressed, $r=0.72$; relaxed, $r=0.77$ ), and we thus concentrated on the higher (systolic) value. As the degree of relaxation was strongly influenced by entry blood pressure $(r=0.38, p<0.001)$, we included the latter as a covariate in our models. According to our prediction of a decrease in relaxation at higher species levels, we tested both a monotonously increasing relationship between plant species richness and stress recovery and the hypothesis of optimal intermediate species richness. Data were analysed by nested analysis of variance with systolic blood pressure immediately after the stress treatment as a covariate. Because the different meadow-like arrays of plants are the replicates for the effect of species richness, we tested the effect of species richness against the variation among the different combinations of plants (arrays). We also tested the effect of the proportion of herbs in an array using a data set without the bare ground treatment against the variation among the arrays. In contrast, because these variables varied among the participants, we tested the effects of gender of the participants, their age, and their degree of self-reported attachment to nature against the residual variation among participants, according to the rules for the analysis of nested designs (Zar, 2010).

Because we were interested in the decrease in blood pressure (relaxation) due to the treatments, we used the difference between systolic blood pressure directly before and after the post-stress relaxation period as a dependent variable with blood pressure before relaxation as a co-variable. However, using final blood pressure as the dependent variable with entry blood pressure as a co-variable resulted in exactly the same $F$ values and $P$ values for the effects of species richness and the demographic variables. All analyses were carried out with IBM SPSS Statistics 24 for Windows.

\section{Results}

As predicted (P1), the decrease in systolic blood pressure was stronger when respondents could view a meadow-like

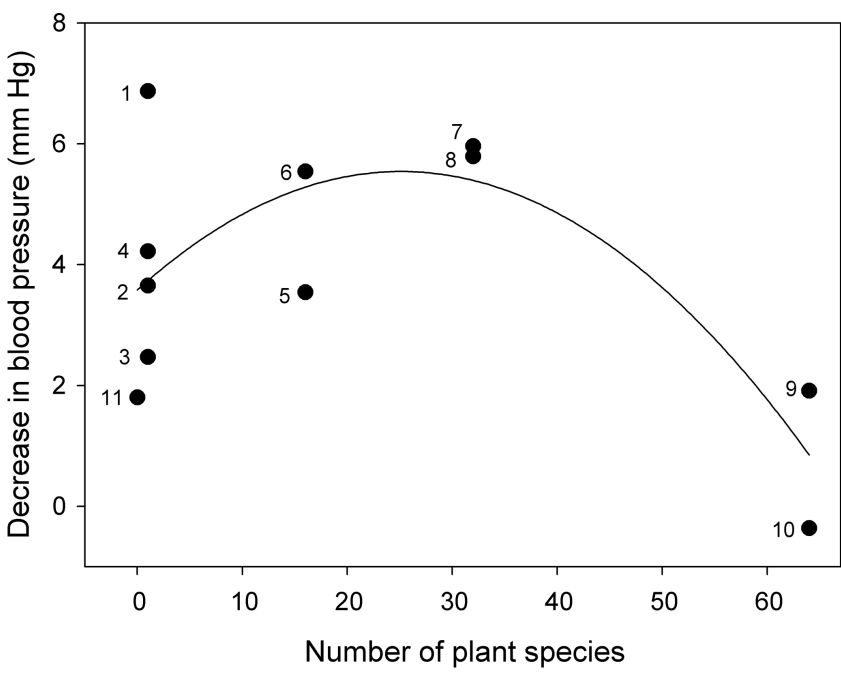

Figure 1. The effect of species richness of meadow-like arrangements of plants on the mean decrease in systolic blood pressure of participants during the relaxation phase after a stress treatment. During their relaxation, participants looked at arrangements of different combinations of plant species and different species richness. Each data point depicts the mean response of participants to a certain arrangement of plants. Effects are adjusted for systolic blood pressure immediately after the stress treatment. The curve shows a quadratic function fitted to the mean responses. The numbers refer to the treatment numbers in Table 1 .

array of plants instead of ground without vegetation (Fig. 1). In the model, relaxation was influenced by systolic blood pressure before the post-stress relaxation period (Table 2). With increasing plant species richness, relaxation increased (P2). However, relaxation was highest at intermediate levels of species richness (32 species; see Fig. 1, Table 2). The effect of the combination of plants was not significant after accounting for differences in species richness (see term combination in Table 2); i.e. there was no effect of the different arrangements on relaxation of blood pressure that was not explained by species richness.

The proportion of herbs had little effect on stress relaxation in addition to the effects of species richness $\left(F_{1,6}=\right.$ $2.87, p=0.141$; P3). However, mean difference in systolic blood pressure was highest when the Papaver rhoeas monoculture was presented (see Fig. 1). Contrary to our prediction (P4), age, gender, and a person's self-reported attachment to nature had no influence on relaxation (all $p>0.234$; see Table 2).

\section{Discussion}

In line with our first prediction (P1) and results from previous studies (e.g. Chang and Chen, 2005; Hartig et al., 2003; Ulrich, 1984; Ulrich et al., 1991), stress recovery was larger when respondents looked at a scene with vegetation (meadow-like array) than at one without (ground without 
Table 2. Nested analysis of variance of the effects of species richness per array, age, nature attachment, and gender on the mean decrease in systolic blood pressure of participants during the relaxation phase after a stress treatment.

\begin{tabular}{lrrrrr}
\hline Source & SS & $\mathrm{d} f$ & $\mathrm{MS}$ & $F$ & Sig. \\
\hline Systolic blood pressure (stressed) & 1526.23 & 1 & 1526.23 & 69.31 & $<0.001$ \\
Species richness (linear term) & 183.69 & 1 & 183.69 & 5.38 & 0.049 \\
Species richness (quadratic term) & 385.94 & 1 & 385.94 & 11.30 & 0.010 \\
Species combination (rest) & 273.24 & 8 & 34.16 & 0.66 & 0.725 \\
Age & 25.72 & 1 & 25.72 & 0.50 & 0.481 \\
Nature attachment & 8.90 & 1 & 8.90 & 0.17 & 0.679 \\
Gender & 73.81 & 1 & 73.81 & 1.43 & 0.234 \\
Error & 8058.90 & 156 & 51.66 & & \\
\hline Total & 10536.42 & 170 & & & \\
\hline
\end{tabular}

vegetation). Moreover, stress recovery was positively related to plant species richness, as predicted. In a British study, people's perceived likelihood of recovery from mental fatigue also increased with perceived plant species richness; however, with actual species richness, no such clear pattern was found (Dallimer et al., 2012). Well-being even declined with greater plant diversity, which is in line with our result for the 64-species array (see P2). The very low effect on relaxation from the 64-species mixtures is in stark contrast to the high appreciation of this diversity level when visual attractiveness was studied (Lindemann-Matthies et al., 2010a). In a large study, meadow-like arrays of different species richness and evenness, but random species composition, were presented to lay people. In addition, two larger-scale field studies using natural meadows were conducted. In both the experiments and the field studies, lay people's aesthetic appreciation always increased with true species richness and did not follow a quadratic trend (Lindemann-Matthies et al., 2010a). In contrast, in the present study relaxation was strongest at an intermediate diversity (32 species) and was much lower at the highest diversity (64 species). The forced view onto the highly diverse array of plants may actually have hindered relaxation. Some of our participants actually described the 64-species mixtures as chaotic, wild, and hardly comforting. The question has been raised whether an increase in the number of plant species results in a consistent increase in people's well-being or if there is a density beyond which there is no increase, or even a decrease, in well-being and relaxation (Shanahan et al., 2015). The dose-response curve could be linear, S-shaped, inverted U-shaped, or have some other shape (as discussed in Jiang et al., 2015; Shanahan et al., 2015; see also Pett et al., 2016). Our result is in line with the notion that the relationship between the dose of nature and the benefit to human health does not monotonously increase in all cases (Barton and Pretty, 2010; Shanahan et al., 2015).

In contrast to our prediction (P3), relaxation did not clearly increase with an increasing herb-to-grass ratio (but see Lindemann-Matthies and Bose, 2007). However, the strongest positive effect on relaxation was found for the poppy (Papaver rhoeas) monoculture. Recent experiments indicate that aesthetic preferences and emotional responses to objects of a certain colour are closely linked (Palmer and Schloss, 2010). This might explain why the poppy monoculture had such a strong effect on relaxation as poppies are clearly attractive to people (Lindemann-Matthies and Bose, 2007; Lindemann-Matthies et al., 2010a). Warm orange and red colours in general were found to be attractive for humans, not only in plants but also in penguins (Stokes, 2007). From previous publications on colour preferences, a different result could also have been expected as longer wavelength colours (red, orange) were regarded as emotionally arousing and shorter wavelength colours (green, blue) were regarded as calming (see discussion in Elliot et al., 2007). However, the few studies on colour effects have been criticized for their lack of conceptual depth (Lichtenfeld et al., 2012).

We did not find influences of age, gender, and a person's attachment to nature on stress relaxation (see P4). Studies have shown that the elderly benefit more than the young from nature activities such as gardening or walking and also derive more aesthetic pleasure from plants and green environments (Collins and O'Callaghan, 2008; Rappe et al., 2006). Most likely, we already had a rather relaxed, nature-attached (scores larger than 8 on the 10-point scale) sample of park walkers.

Our study has certain limitations. The size of our meadowlike arrays was rather small and larger arrangements of plants or natural vegetation might have different effects. We only used 10 different species combinations and thus few replicates for the different levels of species richness. We could not keep the evenness of the species combinations constant, although evenness has been found to affect the appreciation of experimental meadows (Lindemann-Matthies et al., 2010a). Moreover, the overall differences between the stressed and relaxed states were rather small. The number of participants in the study was not large and restricted to visitors of one public park in a large city. Stressful tasks other than the Stroop colour test might have stressed participants more strongly, resulting in more pronounced effects of the different 
diversity levels. However, we did not want to expose participants to more demanding cognitive tests as they took part in the experiment during their leisure time.

\section{Conclusions}

In view of an increasing worldwide urbanization, there are many ways how nature can be brought into urban design (examples for "biophilic cities" in Beatley, 2011). However, just adding green space to cities is not enough. In recent years, green areas are increasingly designed in ways to promote species richness of wild plants and animals (Beatley, 2011; Lindemann-Matthies and Bose, 2007), and it has been pointed out that management measures should consider both ecological quality and human well-being (Jorgensen and Gobster, 2010). In times of increasing stress and cardiovascular diseases it becomes more and more important to offer high-quality green space for relaxation. Our results exemplify that species richness and the presence of certain attractive herbs positively contribute to the well-being of humans by fostering recovery from stress.

Data availability. Data are available as a Supplement.

Supplement. The supplement related to this article is available online at: https://doi.org/10.5194/we-18-121-2018-supplement.

Author contributions. PLM and DM conceived the ideas and designed the experiment, PLM carried out the study, and PLM and DM analysed the data and wrote the manuscript.

Competing interests. The authors declare that they have no conflict of interest.

Acknowledgements. We would like to thank all participants for their time, Theres Zwimpfer for technical support, and Annika Frischauf for help with the data collection.

Edited by: Jutta Stadler

Reviewed by: Roland Brandl and one anonymous referee

\section{References}

Barton, J. and Pretty, J.: What is the best dose of nature and green exercise for improving mental health? A multi-study analysis, Environ. Sci. Technol., 44, 3947-3955, 2010.

Beatley, T.: Biophilic cities. Integrating nature into urban design and planning, Washington DC, Island Press, 2011.

Beukeboom, C. J., Langeveld, D., and Tanja-Dijkstra, K.: Stressreducing effects of real and artificial nature in a hospi- tal waiting room, J. Altern. Complem. Med., 18, 329-333, https://doi.org/10.1089/acm.2011.0488, 2012.

Bratman, G. N., Hamilton, J. P., and Daily, G. C.: The impacts of nature experience on human cognitive function and mental health, Ann. NY Acad. Sci., 1249, 118-136, https://doi.org/10.1111/j.1749-6632.2011.06400.x, 2012.

Bringslimark, T., Hartig, T., and Patil, G. G.: Psychological benefits of indoor plants in workplaces: Putting experimental results into context, HortScience, 42, 581-587, 2007.

Cervinka, R., Röderer, K., and Hefler, E.: Are nature lovers happy? On various indicators of well-being and connectedness with nature, J. Health Psychol., 17, 379-388, https://doi.org/10.1177/1359105311416873, 2012.

Chang, C. Y. and Chen, P. K.: Human response to window views and indoor plants in the workplace, HortScience, 40, 1354-1359, 2005.

Clark, N. E., Lovell, R., Wheeler, B. W., Higgins, S. L., Depledge, M. H., and Norris, K.: Biodiversity, cultural pathways, and human health: a framework, Trends Ecol. Evol. 29, 198-204, https://doi.org/10.1016/j.tree.2014.01.009, 2014.

Collins, C. C. and O'Callaghan, A. M.: The impact of horticultural responsibility on health indicators and quality of life in assisted living, HortTechnology, 18, 611-618, 2008.

Dallimer, M., Irvine, K. N., Skinner, A. M., Davies, Z. G., Rouquette, J. R., Maltby, L. L., Warren, P. H., Armsworth, P. R., and Gaston, K. J.: Biodiversity and the feel-good factor: Understanding associations between self-reported human well-being and species richness, BioScience, 62, 47-55, https://doi.org/10.1525/bio.2012.62.1.9, 2012.

Dijkstra, K., Pieterse, M. E., and Pruyn, A.: Stress-reducing effects of indoor plants in the built healthcare environment: The mediating role of perceived attractiveness, Prev. Med., 47, 279-283, https://doi.org/10.1016/j.ypmed.2008.01.013, 2008.

Elliot, A. J., Maier, M. A., Moller, A. C., Friedman, R., and Meinhardt, J.: Color and psychological functioning: The effect of red on performance attainment, J. Exp. Psychol., 136, 154-168, https://doi.org/10.1037/0096-3445.136.1.154, 2007.

Fuller, R. A., Irvine, K. N., Devine-Wright, P., Warren, P. H., and Gaston, K. J.: Psychological benefits of greenspace increase with biodiversity, Biol. Lett., 3, 390-394, https://doi.org/10.1098/rsbl.2007.0149, 2007.

Han, K.-T.: Influence of limitedly visible leafy indoor plants on the psychology, behavior, and health of students at a junior high school in Taiwan, Environ. Behav., 41, 658-692, https://doi.org/10.1177/0013916508314476, 2009.

Hartig, T., Evans, G. W., Jamner, L. D., Davis, D. S., and Gärling, T.: Tracking restoration in natural and urban field settings, J. Environ. Psychol., 23, 109-123, https://doi.org/10.1016/S02724944(02)00109-3, 2003.

Hector, A., Schmid, B., Beierkuhnlein, C., Caldeira, M. C., Diemer, M., Dimitrakopoulos, P. G., Finn, J. A., Freitas, H., Giller, P. S., Good, J., Harris, R., Högberg, P., Huss-Danell, K., Joshi, J., Jumpponen, A., Körner, C., Leadley, P. W., Loreau, M., Minns, A., Mulder, C. P. H., O’Donovan, G., Otway, S. J., Pereira, J. S., Prinz, A., Read, D. J., Scherer-Lorenzen, M., Schulze, E.-D., Siamantziouras, A.-S., Spehn, E. M., Terry, A. C., Troumbis, A. Y., Woodward, F. I., Yachi, S., and Lawton, J. H.: Plant diversity and productivity experiments in European grasslands, Science, 
286, 1123-1127, https://doi.org/10.1126/science.286.5442.1123, 1999.

Ikei, H., Komatsu, M., Song, C., Himoro, E., and Miyazaki, Y.: The physiological and psychological relaxing effects of viewing rose flowers in office workers, J. Physiol. Anthropol., 33, https://doi.org/10.1186/1880-6805-33-6, 2014.

Jiang, B., Li, D., Larsen, L., and Sullivan, W. C.: A dose-response curve describing the relationship between urban tree cover density and self-reported stress recovery, Environ. Behav., 48, 607629, https://doi.org/10.1177/0013916514552321, 2016.

Jorgensen, A. and Gobster, P. H.: Shades of green: measuring the ecology of urban green space in the context of human health and well-being, Nat. Cult., 5, 338-363, https://doi.org/10.3167/nc.2010.050307, 2010.

Kaplan, R. and Kaplan, S.: The experience of nature. A psychological perspective, New York, NY, Cambridge University Press, 1989.

Kaplan, R., Kaplan, S., and Ryan, R. L.: With people in mind: Design and management of everyday nature, Washington, DC, Island Press, 1998.

Kellert, S. R.: The biological basis for human values of nature, in: The biophilia hypothesis, edited by: Kellert, S. R. and Wilson, E. O., Washington, DC, Island Press, 42-69, 1993.

Larsen, L., Adams, J., Deal, B., Kweon, B. S., and Tyler, E.: Plants in the workplace: The effects of plant density on productivity, attitudes, and perceptions, Environ. Behav., 30, 261-281, https://doi.org/10.1177/001391659803000301, 1998.

Li, D. and Sullivan, W. C.: Impact of views to school landscapes on recovery from stress and mental fatigue, Landscape Urban Plan., 148, 149-158, https://doi.org/10.1016/j.landurbplan.2015.12.015, 2016.

Lichtenfeld, S., Elliot, A. J., Maier, M. A., and Pekrun, R.: Fertile green: Green facilitates creative performance, Pers. Soc. Psychol. B., 38, 784-797, https://doi.org/10.1177/0146167212436611, 2012.

Lindemann-Matthies, P. and Bose, E.: Species richness, structural diversity and species composition in meadows created by visitors of a botanical garden in Switzerland, Landscape Urban Plan., 79, 298-307, https://doi.org/10.1016/j.landurbplan.2006.03.007, 2007.

Lindemann-Matthies, P., Junge, X., and Matthies, D.: The influence of plant diversity on people's perception and aesthetic appreciation of grassland vegetation, Biol. Conserv., 143, 195-202, https://doi.org/10.1016/j.biocon.2009.10.003, 2010a.

Lindemann-Matthies, P., Briegel, R., Schüpbach, B., and Junge, X.: Aesthetic preference for a Swiss alpine landscape: The impact of different agricultural land-use with different biodiversity, Landscape Urban Plan., 98, 99-109, https://doi.org/10.1016/j.landurbplan.2010.07.015, 2010b.

Lohr, V. I., Pearson-Mims, C. H., and Goodwin, G. K.: Interior plants may improve worker productivity and reduce stress in a windowless environment, J. Environ. Hortic., 14, 97-100, 1996.

Maas, J., Verheij, R. A., Groenewegen, P. P., De Vries, S., and Spreeuwenberg, P.: Green space, urbanity, and health: how strong is the relation?, J. Epidemiol. Comm. H., 60, 587-592, https://doi.org/10.1136/jech.2005.043125, 2006.

Millennium Ecosystem Assessment: Ecosystems and human wellbeing: Biodiversity synthesis, Washington DC, World Resources Institute, 2005.
Palmer, S. E. and Schloss, K. B.: An ecological valence theory of human color preference, P. Natl. Acad. Sci. USA, 107, 88778882, https://doi.org/10.1073/pnas.0906172107, 2010.

Park, S. H. and Mattson, R. H.: Therapeutic influences of plants in hospital rooms on surgical recovery, HortScience, 44, 102-105, 2009.

Pett, T. J., Shwartz, A., Irvine, K. N., Dallimer, M., and Davies, Z. G.: Unpacking the people-biodiversity paradox: a conceptual framework, BioScience, 66, 576-583, https://doi.org/10.1093/biosci/biw036, 2016.

Rappe, E., Kivelä, S. L., and Rita, H.: Visiting outdoor green environments positively impacts self-rated health among older people in long-term care, HortTechnology, 16, 55-59, 2006.

Shanahan, D. F., Fuller, R. A., Bush, R., Lin, B. B., and Gaston, K. J.: The health benefits of urban nature: How much do we need?, BioScience, 65, 476-485, https://doi.org/10.1093/biosci/biv032, 2015.

Shibata, S. and Suzuki, N.: Effects of the foliage plant on task performance and mood, J. Environ. Psychol., 22, 265-272, https://doi.org/10.1006/jevp.23, 2002.

Shibata, S. and Suzuki, N.: Effects of an indoor plant on creative task performance and mood, Scand. J. Psychol., 45, 373-381, https://doi.org/10.1111/j.1467-9450.2004.00419.x, 2004.

Southon, G. E., Jorgensen, A., Dunnett, N., Hoyle, H., and Evans, K. L.: Perceived species-richness in urban green spaces: Cues, accuracy and well-being impacts, Landscape Urban Plan., 172, 1-10, https://doi.org/10.1016/j.landurbplan.2017.12.002, 2018.

Stanković, A. and Nikolić, M.: Long-term ambient air pollution exposure and risk of high blood pressure among citizens in Nis, Serbia, Clin. Exp. Hypertens., 38, 119-124, https://doi.org/10.3109/10641963.2015.1060992, 2016.

Stigsdotter, U. K., Ekholm, O., Schipperijn, J., Toftager, M., Kamper-Jørgensen, F., and Randrup, T. B.: Health promoting outdoor environments - Associations between green space, and health, health-related quality of life and stress based on a Danish national representative survey, Scand. J. Public Health, 38, 411-417, https://doi.org/10.1177/1403494810367468, 2010.

Stokes, D. L.: Things we like: human preferences among similar organisms and implications for conservation, Hum. Ecol., 35, 361369, https://doi.org/10.1007/s10745-006-9056-7, 2007.

Tulen, J. H. M., Moleman, P., Van Steenis, H. G., and Boomsma, F.: Characterization of stress reactions to the Stroop Color Word Test, Pharmacol. Biochem. Be., 32, 9-15, https://doi.org/10.1016/0091-3057(89)90204-9, 1989.

Ulrich, R. S.: View through a window may influence recovery from surgery, Science, 224, 420-421, https://doi.org/10.1016/S02724944(05)80184-7, 1984.

Ulrich, R. S.: Biophilia, biophobia and natural landscapes, in: The Biophilia Hypothesis, edited by: Kellert, S. R. and Wilson, E. O., Island Press, Washington DC, 73-137, 1993.

Ulrich, R. S., Simons, R. F., Losito, B. D., Fiorito, E., Miles, M. A., and Zelson, M.: Stress recovery during exposure to natural and urban environments, J. Environ. Psychol., 11, 201-230, 1991.

Van den Berg, A. E., Wesselius, J. E., Maas, J., and TanjaDijkstra, K.: Green walls for a restorative classroom environment: a controlled evaluation study, Environ. Behav., 49, 791813, https://doi.org/10.1177/0013916516667976, 2017. 
WHO (World Health Organization): Constitution of WHO: Principles, available at: http://www.who.int/about/mission/en/, last access: 23 August 2018.
Zar, J. H.: Biostatistical Analysis, 5th. Prentice-Hall/Pearson, Upper Saddle River, NJ, 2010. 